\title{
ASSESSING THE PREVALENCE OF LATENT TUBERCULOSIS AMONG HEALTH CARE PROVIDERS IN ZAGAZIG CITY, EGYPT USING TUBERCULIN SKIN TEST AND QUANTIFERON-TB GOLD IN-TUBE TEST
}

\author{
Rehab H. El-Sokkary', Ashwak M. Abu-Taleb', Omnia S. El-Seifi', Haidy E. Zidan², Eman M. Mortada', Dalia \\ El-Hossary', Salama E. Farag ${ }^{4}$ \\ ${ }^{1}$ Medical Microbiology and Immunology Department, Faculty of Medicine, Zagazig University, Zagazig, Egypt \\ ${ }^{2}$ Department of Community, Environmental and Occupational Medicine, Faculty of Medicine, Zagazig University, Zagazig, Egypt \\ ${ }^{3}$ Biochemistry Department, Faculty of Medicine, Zagazig University, Zagazig, Egypt \\ ${ }^{4}$ Department of Internal Medicine, Faculty of Medicine, Zagazig University, Zagazig, Egypt
}

\section{SUMMARY}

Aim: Early detection of latent tuberculosis infection (LTBI) will prevent development of active TB among health care providers. The aim of the study was to assess the prevalence of LTBI among health care providers and compare the QuantiFERON-TB Gold In-Tube Test (QFT-GIT) and Tuberculin skin test in efforts to detect LTBI and to investigate possible associated risk factors of infection.

Methods: A cross sectional study was carried out during the period of 6 months in the Chest Hospital in Zagazig city and the Nephrology Unit at Zagazig University Hospitals in 132 randomly selected health care providers who were examined for LTBI by QFT-GIT and Tuberculin skin test and for the associated risk factors as well.

Results: The prevalence of LTBI identified by QFT-GIT and by Tuberculin skin test was $28.8 \%$ and $59.1 \%$, respectively. Poor agreement was observed between the two tests $(\mathrm{kappa}=0.10)$. Working more than 10 years, being nurse, diabetic and smoker were risk factors significantly associated with LTBI $(p<0.05)$.

Conclusions: QFT-GIT is considered a useful tool in detecting LTBI cases, especially in a country where BCG vaccination is a national policy (as in Egypt). Duration of work, profession, diabetes and smoking are the risk factors for LTBI. Active surveillance and infection control measures are recommended to reduce the risk of LTBI.

Key words: prevalence, tuberculosis, Quantiferon, Tuberculin skin test, health care providers

Address for correspondence: O. S. El-Seifi, Department of Environmental and Occupational Medicine, Zagazig University, Zagazig, Egypt. E-mail: omnia2200@yahoo.com

\section{INTRODUCTION}

Tuberculosis remains an important public health problem in Egypt. Egypt is ranked among the mid-level incidence countries, with TB prevalence reported by the World Health Organization (WHO) to be 29 per 100,000 population in 2013 (1). Tuberculosis is an occupational disease often detected among health care providers. Their continuous exposure to tuberculosis patients together with working in poorly ventilated spaces make them more vulnerable to the risk of infection (2). Once the infection with tuberculosis bacilli occurred, active disease develops in about $10 \%$ of cases. The remaining $90 \%$ stays in a state of latent tuberculosis infection (3).

Diagnosis of latent tuberculosis infection aims mainly at providing early treatment of the condition to prevent the development of active tuberculosis. Yet, it has been held back by the lack of a gold standard test due to the low number of dormant tubercle bacilli, not directly detectable or quantifiable. Latent tuberculosis infection results in an asymptomatic state with no clinical or radiological evidence of active tuberculosis but with survival of inactive bacilli in tissues (4).
For more than 100 years, Tuberculin skin test was the only method available for the diagnosis of latent tuberculosis infection (5). With the advances in the field of genomics and immunology, new diagnostic tests named QuantiFERON $®$-TB Gold In-Tube have emerged. They are characterized by higher specificity than the Tuberculin skin test (6). Using these tests reduced the risk of latent tuberculosis infection overestimation (due to cross-reactions with BCG vaccination or exposure to environmental mycobacteria). This made the investigations of people repeatedly exposed to tuberculosis (e.g. health care providers) more feasible (7).

The asymptomatic nature of latent tuberculosis infection, a lack of accurate diagnostic test and the relatively high cost of using QuantiFERON-TB Gold In-Tube Test (QFT-GIT) appeared as obstacles in many healthcare facilities in developing countries leading to overlooking the disease and its risk factors among health care providers especially those serving immunecompromised patients (8). The objectives of the study were to assess the prevalence of latent tuberculosis infection among health care providers, to compare QFT-GIT and Tuberculin skin test in diagnosis of latent tuberculosis and to determine the associated risk factors. 


\section{MATERIALS AND METHODS}

\section{Design and Settings}

A cross-sectional study was carried out during the period of 6 months (August 2012 - January 2013) in Chest Hospital (the only specialized hospital for tuberculosis in our district) and $\mathrm{Ne}$ phrology Unit (where immune-compromised patients are treated with dialysis and where cases of tuberculosis were previously detected in this group of patients) at Zagazig University Hospitals, Zagazig city, Egypt.

\section{Subjects and Sampling Technique}

Our subjects were nurses and laboratory technicians as they are at greater risk of TB infection due to their direct contact with patients and their specimens (9). Sample size calculation using the EPI info version 6 was carried out depending on the total number of nurses and laboratory technicians during the study in the selected places. From the total of 231, 157 were nurses in Chest Hospital, 56 nurses in Nephrology Unit and 18 Chest Hospital's laboratory technician. The prevalence of latent tuberculosis infection among nurses and laboratory technicians found in the pilot study was $10.6 \%$, at $95 \%$ confidence interval and a power of $80.0 \%$. Depending on that 132 randomly selected nurses and laboratory technicians were recruited for this study by stratified random technique from both hospital settings. The final sample included 76 nurses who were in contact with tuberculosis patients (Chest Hospital), 40 nurses who were in contact with immunecompromised patients (Nephrology Unit) and 16 laboratory technicians responsible for laboratory analysis of specimens of tuberculosis patients (Chest Hospital). Those who have active disease or history of TB and those with incomplete questionnaire were excluded from the study. All our subjects were interviewed and underwent laboratory investigation by Tuberculin skin test and QFT-GIT tests with high response rate of $81 \%$. Those with positive test results were informed about these findings. A pilot study to assess the prevalence of the disease and to test consistency of the questionnaire was conducted prior to our study on 45 nurses and laboratory technicians who were not included in the final analysis. The cronbach's alpha was 0.82 .

\section{Tools of the Study \\ Questionnaire}

Self administered questionnaire was used to obtain information about health care workers and possible risk factors. The items of the questionnaire based on the previous literature (10) asked about age, gender, profession, working duration, family history of TB, presence of HCV infection, history of BCG vaccination (verified by the presence of scar), presence of diabetes mellitus and history of smoking.

\section{Laboratory Tests: QFT-GIT, Tuberculin Skin Test \\ 1-Interferon-Gamma Assay (IFN $)$ Assay by QFT-GIT}

For each case, 3 heparinized blood collection tubes were used. The first tube was precoated with three tuberculosis-specific antigens (ESAT-6, CFP-10 and TB7.7). The second tube was precoated with phytohemagglutinin, and the third tube was coated with anticoagulant only (negative control tube). Three milliliters of blood were collected prior to Tuberculin skin test administration, incubated overnight at $37^{\circ} \mathrm{C}$ and then centrifuged for $10 \mathrm{~min}$. Plasma samples were tested by ELISA. According to the supplier's instruction, a value $\geq 0.35 \mathrm{IU} / \mathrm{mL}$ for (IFN- $\gamma$ in the TB antigen tube) - (IFN- $\gamma$ in the negative control tube) was considered a positive result. If the IFN- $\gamma$ level was $<0.35 \mathrm{IU} / \mathrm{mL}$ in the TB antigen tube and mitogen control was positive $(\geq 0.5$ $\mathrm{IU} / \mathrm{mL}$ ), the test was recorded as negative (11).

\section{Tuberculin Skin Test}

Tuberculin skin test was performed using $0.1 \mathrm{~mL}$ of 5 tuberculin units PPD (Vacsera), and read between 48 and 72 hours after administration. A reaction of induration (palpable, raised, hardened area or swelling) $\geq 10 \mathrm{~mm}$ was considered positive (12).

\section{Ethical Consideration}

Permission for conduction of the study was obtained from each hospital director before data collection. Participation in the study was voluntary and written informed consent was obtained before data collection and laboratory investigations.

\section{Statistical Analysis}

Data were coded and statistically analyzed using computerized software statistical packages SPSS version 19 (13). Description and summarization of data were performed using percent, mean and standard deviation. Chi-square (or Fisher's exact tests if the expected frequency in any cell was $<5$ ) was calculated to detect the possible association between potential risk factors and development of latent tuberculosis infection. McNemar Chi-square test was calculated to measure association between Tuberculin skin test and QFT-GIT results and agreement between both was assessed by kappa where $\kappa>0.75$ represent excellent agreement, $\kappa$ values from $0.4-0.75$ represent fair to good agreement and $\kappa<0.4$ represent poor agreement (14). Logistic regression was performed to detect the main independent predictors for QFT-GIT results. $P$ value $\leq 0.05$ was considered a significant difference.

\section{RESULTS}

Regarding the general characteristics of the participants, the majority of participants were chest nurses $(57.6 \%)$ followed by nephrology nurses $(30.3 \%)$ and laboratory technicians (12.1\%). The mean duration of work in particular profession and setting was $10.7 \pm 8.2$, most of the workers have a negative family history for TB (95.5\%), negative HCV infection (93.9\%), positive history of BCG vaccination (92.4\%), no diabetes mellitus $(77.3 \%)$, and were non smokers $(77.3 \%)$ (Table 1$)$.

The association between Tuberculin skin test and QFT-GIT results is presented in Table 2, where the statistical significant difference between results of both tests $(p<0.001)$ is shown. The prevalence of latent tuberculosis diagnosed by QFT-GIT was $28.8 \%$, while $59.1 \%$ were confirmed by Tuberculin skin test. The overall agreement between the results of two tests was $51.5 \%$, with kappa 0.10 which is considered a poor agreement with no significant difference (Table 3). 
Table 1. General characteristics of the studied health care providers $(N=132)$

\begin{tabular}{|c|c|c|}
\hline Item & $n$ & $\%$ \\
\hline $\begin{array}{l}\text { Age } \\
\text { Mean age (SD) years }\end{array}$ & \multicolumn{2}{|c|}{$35.2(8.99)$} \\
\hline$<35$ year & 72 & 54.5 \\
\hline$\geq 35$ year & 60 & 45.5 \\
\hline \multicolumn{3}{|l|}{ Gender } \\
\hline Female & 102 & 77.3 \\
\hline Male & 30 & 22.7 \\
\hline \multicolumn{3}{|l|}{ Profession } \\
\hline \multicolumn{3}{|l|}{ Nurses } \\
\hline Nephrology & 40 & 30.3 \\
\hline Chest & 76 & 57.6 \\
\hline Laboratory technicians & 16 & 12.1 \\
\hline $\begin{array}{l}\text { Duration of work } \\
\text { mean (SD) years }\end{array}$ & \multicolumn{2}{|c|}{$10.1(1.2)$} \\
\hline$<10$ years & 42 & 31.8 \\
\hline$\geq 10$ years & 90 & 68.2 \\
\hline \multicolumn{3}{|c|}{ Family history of tuberculosis } \\
\hline Positive & 6 & 4.5 \\
\hline Negative & 126 & 95.5 \\
\hline \multicolumn{3}{|l|}{ Presence of HCV infection } \\
\hline Positive & 8 & 6.1 \\
\hline Negative & 124 & 93.9 \\
\hline \multicolumn{3}{|l|}{ History of BCG vaccination } \\
\hline Positive & 122 & 92.4 \\
\hline Negative & 10 & 7.6 \\
\hline \multicolumn{3}{|l|}{ Diabetes mellitus } \\
\hline Yes & 30 & 22.7 \\
\hline No & 102 & 77.3 \\
\hline \multicolumn{3}{|l|}{ Smoking } \\
\hline Yes & 30 & 22.7 \\
\hline No & 102 & 77.3 \\
\hline
\end{tabular}

Table 2. Association between Tuberculin skin test and QFTGIT results $(N=132)$

\begin{tabular}{|l|c|c|c|}
\hline \multirow{2}{*}{} & \multicolumn{2}{|c|}{ QFT-GIT } & \multirow{2}{*}{ Total } \\
\cline { 2 - 3 } & Positive & Negative & \\
\hline Tuberculin skin test \\
\hline Positive & $26(19.7 \%)$ & $52(39.4 \%)$ & $78(59.1 \%)$ \\
\hline Negative & $12(9.1 \%)$ & $42(31.8 \%)$ & $54(40.9 \%)$ \\
\hline Total & $38(28.8 \%)$ & $94(71.2 \%)$ & $132(100.0 \%)$ \\
\hline
\end{tabular}

McNemar chi square $=25.00, p<0.001$

Table 3. Agreement between QFT-GIT and Tuberculin skin test in the studied groups

\begin{tabular}{|l|c|c|c|}
\hline Group & $\begin{array}{c}\text { Overall } \\
\text { agreement }\end{array}$ & Kappa & p \\
\hline All & $51.5 \%$ & 0.10 & 0.166 \\
\hline
\end{tabular}

Table 4 shows the association between the studied risk factors and Tuberculin skin test results in the studied groups, with significant difference noted only for the profession, duration of work and BCG vaccination. The association between risk factors and QFT-GIT test results in the studied groups is presented in Table 5 , where the profession, duration of work, diabetes mellitus, and smoking appear as significant risk factors.

Logistic regression for factors that significantly predict the results of QFT-GIT test revealed that the profession, duration of work, family history of tuberculosis and diabetes mellitus were the only independent predictors for QFT-GIT test results among the studied group (Table 6).

\section{DISCUSSION}

Examining the health care providers for latent tuberculosis infection is an important step for the identification of cases with a high risk of future disease (15). To our knowledge this study is one of few Egyptian studies that assess latent tuberculosis infection by different diagnostic tests especially by QFT-GIT. Most previous Egyptian studies dealt with active tuberculosis in patients.

One hundred and thirty two health care workers were enrolled in our study, 28.8\% were positive for latent tuberculosis infection by QFT-GIT. The results coincide with Topic et al. who found out $31 \%$ (16). On the other hand, a higher percentage $(59.1 \%)$ of our sample was positive for latent tuberculosis infection by Tuberculin skin test. This was comparable to Costa et al. (17) who found out $44.4 \%$ and another study from Switzerland which reported $48 \%$ (18). The difference between QFT-GIT (28.8\%) and Tuberculin skin test $(59.1 \%)$ was in accordance with similar previous studies $(1,19)$. Higher percentage of tuberculin positivity could be explained by the inability of Tuberculin skin test to discriminate between latent tuberculosis infection, BCG vaccination and infection by non tuberculous mycobacteria and probable false positivity of tests used (20).

Poor agreement $(51.5 \%)$ between Tuberculin skin test and QFT-GIT with kappa value 0.10 agreed with other researchers $(10,21)$ who found that the concordance between Tuberculin skin test and QFT-GIT was 50.5\% with poor kappa value $<0.12$. This indicated that Tuberculin skin test should not replace QFT-GIT in the diagnosis of latent tuberculosis infection in the studied group.

Among risk factors associated with latent tuberculosis infection, it was found that positive results of our two tests were higher in older age groups ( $>35$ years old) which agreed with other similar study that declared that age was an independent risk factor for tuberculosis and the prevalence of latent tuberculosis infection in health care workers increased by 1.04 times for each year of age (22).

Duration of work longer than 10 years was associated with a significantly higher prevalence of latent tuberculosis infection among the studied groups by both tests. This was also in agreement with the results of previous studies which stated that the prevalence of latent tuberculosis infection in health care providers increased by 1.5 to 2.4 times with employment duration of more than 1 year, while it was 3 -fold higher with 10 years of employment $(23,24)$. This could be explained by longer time of continuous exposure (1). 
Table 4. Association between studied risk factors and Tuberculin skin test results in the studied groups $(N=132)$

\begin{tabular}{|c|c|c|c|c|c|c|}
\hline \multirow{3}{*}{ Risk factors } & \multicolumn{4}{|c|}{ Tuberculin skin test } & \multirow{3}{*}{$x^{2}$} & \multirow{3}{*}{$p$} \\
\hline & \multicolumn{2}{|c|}{ Positive ( $\geq 10 \mathrm{~mm}, \mathrm{~N}=78$ ) } & \multicolumn{2}{|c|}{ Negative (<10 mm, N=54) } & & \\
\hline & $\mathrm{n}$ & $\%$ & $\mathrm{n}$ & $\%$ & & \\
\hline \multicolumn{7}{|l|}{ Age } \\
\hline$<35$ year & 34 & 43.6 & 28 & 51.9 & \multirow{2}{*}{0.87} & \multirow{2}{*}{0.349} \\
\hline$\geq 35$ year & 44 & 56.4 & 26 & 48.1 & & \\
\hline \multicolumn{7}{|l|}{ Sex } \\
\hline Female & 58 & 74.4 & 44 & 81.5 & \multirow{2}{*}{0.92} & \multirow{2}{*}{0.337} \\
\hline Male & 20 & 25.6 & 10 & 18.5 & & \\
\hline \multicolumn{7}{|l|}{ Profession } \\
\hline \multicolumn{5}{|l|}{ Nurses } & \multirow{4}{*}{28.63} & \multirow{4}{*}{$<0.001^{\text {*** }}$} \\
\hline Nephrology & 10 & 12.8 & 30 & 55.6 & & \\
\hline Chest & 58 & 74.4 & 18 & 33.3 & & \\
\hline Laboratory technicians & 10 & 12.8 & 6 & 11.1 & & \\
\hline \multicolumn{7}{|l|}{ Duration of work } \\
\hline$<10$ years & 16 & 20.5 & 26 & 48.1 & \multirow{2}{*}{11.23} & \multirow{2}{*}{$<0.001^{* * \star}$} \\
\hline$\geq 10$ years & 62 & 79.5 & 28 & 51.9 & & \\
\hline \multicolumn{7}{|c|}{ Family history of tuberculosis } \\
\hline Yes & 4 & 5.1 & 2 & 3.7 & \multirow{2}{*}{$\#$} & \multirow{2}{*}{1.000} \\
\hline No & 74 & 94.4 & 52 & 96.3 & & \\
\hline \multicolumn{7}{|l|}{ BCG vaccination } \\
\hline Yes & 78 & 100.0 & 44 & 81.5 & \multirow{2}{*}{ \# } & \multirow{2}{*}{$<0.001^{* * *}$} \\
\hline No & 0 & 0.0 & 10 & 18.5 & & \\
\hline \multicolumn{7}{|l|}{$\mathrm{HCV}$} \\
\hline Yes & 2 & 2.6 & 6 & 11.1 & \multirow{2}{*}{ \# } & \multirow{2}{*}{0.062} \\
\hline No & 76 & 97.4 & 48 & 88.9 & & \\
\hline \multicolumn{7}{|l|}{ Diabetes mellitus } \\
\hline Yes & 22 & 28.2 & 8 & 14.8 & \multirow{2}{*}{3.25} & $0 \cap 71$ \\
\hline No & 56 & 71.8 & 46 & 85.2 & & 0.011 \\
\hline Smoking & & & & & & \\
\hline Yes & 20 & 25.6 & 10 & 18.5 & ת0? & ?0? \\
\hline No & 58 & 74.4 & 44 & 81.5 & 0.92 & 0.92 \\
\hline
\end{tabular}

${ }^{* *}$ Significance difference $(p<0.001)$, \#Fisher's exact test was used

Regarding profession as a risk factor, latent tuberculosis infection by both tests was significantly higher among nurses. The results are in agreement with previous studies which reported that the prevalence of latent tuberculosis infection in nurses was higher than that in other health care workers (25). Results revealed that a higher percentage of infection was present among chest nurses. This was because they provided care for tuberculosis patients and were continuously directly exposed. Yet the interesting finding was the non-negligible percentage of infections among Nephrology Unit nurses who were in contact with patients undergoing renal dialysis (immunocompromised ones) whose health state make them prone to TB. The latter finding might be an alarming bell about this group of nurses who should be put under supervision.

People with diabetes had a 2-3 times higher risk of tuberculosis compared to people without diabetes. In the study by Jeon and
Murray, QFT-GIT test confirmed that diabetics were at higher risk for latent tuberculosis infection (26). This was in agreement with a previous study which stated that latent tuberculosis infection was detected by IFN- $\gamma$ release assay rather than by Tuberculin skin test in diabetic nurses (27). Also, it was observed that the positive results of QFT-GIT test were significantly higher among smokers, the same results were reported in a study conducted in the United States (28). These findings coincide with the concept of increased susceptibility to tuberculosis by decreased immunity (diabetes) or disturbed cilia function (smoking).

Family history of tuberculosis represents a higher risk of developing latent tuberculosis infection by two tests which is in accordance with the results of another similar study conducted in the United States (29). This could be explained by the fact that these individuals shared the same air and were in close contact when living in the same house. 
Table 5. Association of risk factors and QFT-GIT test results in the studied groups

\begin{tabular}{|c|c|c|c|c|c|c|}
\hline \multirow{3}{*}{ Risk factors } & \multicolumn{4}{|c|}{ QFT-GIT } & \multirow{3}{*}{$x^{2}$} & \multirow{3}{*}{$\mathrm{p}$} \\
\hline & \multicolumn{2}{|c|}{ Positive $(\mathrm{N}=38)$} & \multicolumn{2}{|c|}{ Negative $(\mathrm{N}=94)$} & & \\
\hline & $\mathrm{n}$ & $\%$ & $\mathrm{n}$ & $\%$ & & \\
\hline \multicolumn{7}{|l|}{ Age } \\
\hline$<35$ year & 22 & 57.9 & 50 & 53.2 & \multirow{2}{*}{0.24} & \multirow{2}{*}{0.623} \\
\hline$\geq 35$ year & 16 & 42.1 & 44 & 46.8 & & \\
\hline \multicolumn{7}{|l|}{ Sex } \\
\hline Female & 26 & 68.4 & 76 & 80.9 & \multirow{2}{*}{2.38} & \multirow{2}{*}{0.122} \\
\hline Male & 12 & 31.6 & 18 & 19.1 & & \\
\hline \multicolumn{7}{|l|}{ Profession } \\
\hline \multicolumn{5}{|l|}{ Nurses } & \multirow{4}{*}{6.22} & \multirow{4}{*}{$0.044^{*}$} \\
\hline Nephrology & 6 & 15.8 & 34 & 36.2 & & \\
\hline Chest & 28 & 73.7 & 48 & 51.1 & & \\
\hline Laboratory technicians & 4 & 10.5 & 12 & 12.7 & & \\
\hline \multicolumn{7}{|l|}{ Duration of work } \\
\hline$<10$ years & 28 & 73.7 & 34 & 36.2 & \multirow{2}{*}{15.28} & \multirow{2}{*}{$<0.001^{* * *}$} \\
\hline$\geq 10$ years & 10 & 26.3 & 60 & 63.8 & & \\
\hline \multicolumn{7}{|c|}{ Family history of tuberculosis } \\
\hline Yes & 4 & 10.5 & 2 & 2.1 & \multirow{2}{*}{$\#$} & \multirow{2}{*}{0.056} \\
\hline No & 34 & 89.5 & 92 & 97.9 & & \\
\hline \multicolumn{7}{|l|}{ BCG vaccination } \\
\hline Yes & 36 & 94.7 & 86 & 91.5 & \multirow{2}{*}{$\#$} & \multirow{2}{*}{0.723} \\
\hline No & 2 & 5.3 & 8 & 8.5 & & \\
\hline \multicolumn{7}{|l|}{$\mathrm{HCV}$} \\
\hline Yes & 2 & 5.3 & 6 & 6.4 & \multirow{2}{*}{$\#$} & \multirow{2}{*}{1.000} \\
\hline No & 36 & 94.7 & 88 & 93.6 & & \\
\hline \multicolumn{7}{|l|}{ Diabetes mellitus } \\
\hline Yes & 20 & 52.6 & 10 & 10.6 & \multirow{2}{*}{27.17} & $<\cap 001 * * *$ \\
\hline No & 18 & 47.4 & 84 & 89.4 & & \\
\hline Smoking & & & & & & \\
\hline Yes & 22 & 57.9 & 8 & 8.5 & 2757 & 80001 *** \\
\hline No & 16 & 42.1 & 86 & 91.5 & וI.Jו & 0.001 \\
\hline
\end{tabular}

${ }^{*} p<0.05,{ }^{* *}$ Significance difference $(p<0.001)$, "Fisher's exact test was used

Table 6. Logistic regression for factors significantly predicting results of QFT-GIT test in the studied groups

\begin{tabular}{|l|c|c|c|c|c|c|}
\hline & \multirow{2}{*}{} & B & SE & p & \multirow{2}{*}{ Expected (B) } & \multicolumn{2}{|c|}{$95 \%$ Cl for Exp B } \\
\cline { 4 - 8 } & & & & & Lower & Upper \\
\hline Profession & 2.245 & 0.871 & 0.010 & 9.445 & 1.714 & 52.038 \\
\hline Duration of work & 1.296 & 0.603 & 0.032 & 3.653 & 1.120 & 11.918 \\
\hline Family history of tuberculosis & 1.776 & 0.876 & 0.042 & 5.909 & 1.062 & 32.876 \\
\hline Diabetes mellitus & 1.776 & 0.787 & 0.024 & 0.169 & 0.036 & 0.791 \\
\hline Constant & 2.117 & 1.398 & 0.130 & 0.120 & & \\
\hline
\end{tabular}

The results of Tuberculin skin test in BCG vaccinated individuals were significantly affected by their BCG vaccination status. Higher proportions of vaccinated individuals were positive when tested by Tuberculin skin test, whilst the results of individuals tested by QFT-GIT were not affected by vaccination status. This could be due to the fact that QFT-GIT depended on specific M. tuberculosis antigens not affected by vaccination status. Therefore, it reduced the risk of latent tuberculosis infection overestimation via cross-reactions with $\mathrm{BCG}$ vaccination or environmental mycobacteria. These findings made examination by QFT-GIT in 
people who were repeatedly exposed to tuberculosis (e.g. health care providers) more feasible. QFT-GIT is therefore a useful tool in detecting latent tuberculosis infection cases in a country where BCG vaccination is a national policy (as Egypt). However, its much higher cost than that of Tuberculin skin test may be the cause that hinders its use (30).

The results of regression analysis proved that profession, duration of work, family history of tuberculosis and diabetes mellitus are the significant predictors of positive results by QFT-GIT among the studied group. This necessitates more attention to the health care providers with those risk factors when looking for LTBI. Their examination should be provided mainly by QFT-GIT.

\section{CONCLUSION}

Latent tuberculosis infection constitutes a risk for health care providers with a prevalence of $28.8 \%$ by QFT-GIT and $59.1 \%$ by Tuberculin skin test. False positive results of Tuberculin skin test and poor agreement between both tests hindered its use as the only diagnostic test. Working more than 10 years, being a nurse, diabetic and smoker increase the risk of having latent tuberculosis infection. BCG vaccination affects the results obtained by Tuberculin skin test but not QFT-GIT test, which makes QFT-GIT a useful tool in detecting latent tuberculosis infection cases in a country where BCG vaccination is a national policy (as Egypt).

\section{Recommendations}

- Intense surveillance for early diagnosis of TB is required for those working in high-risk areas and also for those working in wards with immunocompromised patients.

- Considering the limitations of Tuberculin skin test (TST) and QFT-GIT, the best solution seems to be the use of both, using the QFT-GIT higher specificity for confirming a positive TST, taking advantage of the best characteristics of each test.

- Health care providers and relevant authorities should continuously strive towards improving preventive and control measures to reduce the risk of transmission of nosocomial TB.

\section{Limitations of the study}

As there is no diagnostic gold standard for latent tuberculosis infection, we could not perfectly assess the sensitivity and specificity of tests used in the study. The only diagnostic standard for latent tuberculosis infection is the eventual development of active tuberculosis, so further longitudinal cohort studies will be needed to follow clinical outcomes of the tested individuals.

\section{Acknowledgement}

We are so grateful to all individuals who participated on this study and the Academic Research of Zagazig University Projects Unit for partially funding this work.

\section{Conflict of Interests}

None declared

\section{Sponsorship}

This work was partially funded by support of academic research of Zagazig University Projects, Zagazig University Postgraduate and Research Affairs.

\section{Ethical Approval}

Permission for conduction of the study was obtained from each hospital director before data collection. Participation in the study was voluntary and written informed consent was obtained prior to data collection and laboratory investigations.

\section{Declaration}

Part of this work was presented at the 3rd Southeast European Conference on Chemotherapy in Dubrovnik, Croatia, 8-11 November 2012.

\section{REFERENCES}

1. Whitaker JA, Mirtskhulava V, Kipiani M, Harris DA, Tabagari N, Kempker RR, et al. Prevalence and incidence of latent tuberculosis infection in georgian healthcare workers. PLoS One. 2013;8(3):e58202.

2. Baussano I, Bugiani M, Carosso A, Mairano D, Pia Barocelli A, Tagna $\mathrm{M}$, et al. Risk of tuberculin conversion among healthcare workers and the adoption of preventive measures. Occup Environ Med. 2007 Mar;64(3):161-6.

3. Al Jahdali HH, Baharoon S, Abba AA, Memish ZA, Alrajhi AA, AlBarrak A, et al. Saudi guidelines for testing and treatment of latent tuberculosis infection. Ann Saudi Med. 2010 Jan-Feb;30(1):38-49.

4. Lalvani A. Diagnosing tuberculosis infection in the 21 st century: new tools to tackle an old enemy. Chest. 2007 Jun;131(6):1898-906.

5. Barsegian V, Mathias KD, Wrighton-Smith P, Grosse-Wilde H, Lindemann M. Prevalence of latent tuberculosis infection in German radiologists. J Hosp Infect. 2008 May;69(1):69-76.

6. Menzies D, Pai M, Comstock G. Meta-analysis: new tests for the diagnosis of latent tuberculosis infection: areas of uncertainty and recommendations for research. Ann Intern Med. 2007 Mar; 146(5):340-54.

7. Lalvani A, Pareek M. Interferon gamma release assays: principles and practice. Enferm Infecc Microbiol Clin. 2010 Apr;28(4):245-52.

8. Chapman AL, Munkanta M, Wilkinson KA, Pathan AA, Ewer K, Ayles $\mathrm{H}$, et al. Rapid detection of active and latent tuberculosis infection in HIV-positive individuals by enumeration of Mycobacterium tuberculosisspecific T cells. AIDS. 2002 Nov 22;16(17):2285-93.

9. García-García ML, Jiménez-Corona A, Jiménez-Corona ME, FerreyraReyes L, Martínez K, Rivera-Chavira B, et al. Factors associated with tuberculin reactivity in two general hospitals in Mexico. Infect Control Hosp Epidemiol. 2001 Feb;22(2):88-93.

10. Rafiza S, Rampal KG, Tahir A. Prevalence and risk factors of latent tuberculosis infection among health care workers in Malaysia. BMC Infect Dis. 2011 Jan 18;11:19.

11. Cellestis. QuantiFERON-TB Gold (In-Tube Method) package insert for in vitro diagnostic use. [Internet]. August 2006 [cited 2011 Dec 16]. Available from: http://www.cellestis.com/IRM/Company/ShowPage. aspx?CPID $=1171$.

12. American Thoracic Society. Targeted tuberculin testing and treatment of latent tuberculosis infection. Am J Respir Crit Care Med. 2000 Apr; 161 Suppl 3: S221-S47.

13. IBM. IBM SPSS Statistics 19 Core System Users' Guide. Chicago: SPSS Inc.; c1989, 2010.

14. Kraemer HC. Measurement of reliability for categorical data in medical research. Stat Methods Med Res. 1992;1(2):183-99.

15. Costa JT, Silva R, Sá R, Cardoso MJ, Ferreira J, Ribeiro C, et al. Tuberculosis - risk of continued transmission in healthcare workers. Rev Port Pneumol. 2010 Jan-Feb;16(1):5-21.

16. Topić RZ, Dodig S, Zoricić-Letoja I. Interferon-gamma and immunoglobulins in latent tuberculosis infection. Arch Med Res. 2009 Feb;40(2):103-8.

17. Casas I, Esteve M, Guerola R, García-Olivé I, Ruiz-Manzano J. A study of tuberculosis infection in workers at a university general hospital: associated factors and evolution in 20 years. Arch Bronconeumol. 2011 Nov;47(11):541-6. (In Spanish.) 
18. Tissot F, Zanetti G, Francioli P, Zellweger JP, Zysset F. Influence of bacille Calmette-Guérin vaccination on size of tuberculin skin test reaction: to what size? Clin Infect Dis. 2005 Jan 15;40(2):211-7.

19. Abu-Taleb AM, El-Sokkary RH, El Tarhouny SA. Interferon-gamma release assay for detection of latent tuberculosis infection in casual and close contacts of tuberculosis cases. East Mediterr Health J. 2011 Oct; 17(10):749-53.

20. Al-Orainey IO. Diagnosis of latent tuberculosis: Can we do better? Ann Thorac Med. 2009 Jan;4(1):5-9.

21. González-Salazar F, Vargas-Villarreal J, Garcialuna-Martínez FJ, Rivera G, Moreno-Treviño MG, Montfort-Gardeazabal JM, et al. Snapshot of Quantiferon TB gold testing in Northern Mexico. Tuberculosis (Edinb). 2011 Dec;91 Suppl 1:S34-7.

22. Abbas MA, AlHamdan NA, Fiala LA, AlEnezy AK, AlQahtani MS Prevalence of latent TB among health care workers in four major tertiary care hospitals in Riyadh, Saudi Arabia. J Egypt Public Health Assoc. 2010;85(1-2):61-71.

23. Zhang X, Jia H, Liu F, Pan L, Xing A, Gu S, et al. Prevalence and risk factors for latent tuberculosis infection among health care workers in China: a cross-sectional study. PLoS One. 2013 Jun 18;8(6):e66412.

24. Pai M. Alternatives to the tuberculin skin test: interferon-gamma assays in the diagnosis of mycobacterium tuberculosis infection. Indian J Med Microbiol. 2005 Jul;23(3):151-8.
25. Yanai H, Limpakarnjanarat K, Uthaivoravit W, Mastro TD, Mori T, Tappero JW. Risk of Mycobacterium tuberculosis infection and disease among health care workers, Chiang Rai, Thailand. Int J Tuberc Lung Dis. 2003 Jan; 7(1):36-45.

26. Jeon CY, Murray MB. Diabetes mellitus increases the risk of active tuberculosis: a systematic review of 13 observational studies. PLoS Med. 2008 Jul 15;5(7):e152.

27. Dodig S, Zrinski Topić R, Živčić J. Latent tuberculosis infection in a subject with diabetes mellitus - a case report. Biochem Med (Zagreb). 2008;18(3):368-73.

28. Bennett DE, Courval JM, Onorato I, Agerton T, Gibson JD, Lambert L, et al. Prevalence of tuberculosis infection in the United States population: the national health and nutrition examination survey, 1999-2000. Am J Respir Crit Care Med. 2008 Feb 1;177(3):348-55.

29. Haley CA, Cain KP, Yu C, Garman KF, Wells CD, Laserson KF. Riskbased screening for latent tuberculosis infection. South Med J. 2008 Feb;101(2):142-9.

30. Dheda K, Chang JS, Kim LU, Huggett JF, Johnson MA, Zumla A, et al. Interferon gamma assays for tuberculosis. Lancet Infect Dis. 2005 Jun;5(6):324-5.

Received September 11, 2014 Accepted in revised form January 19, 2015 